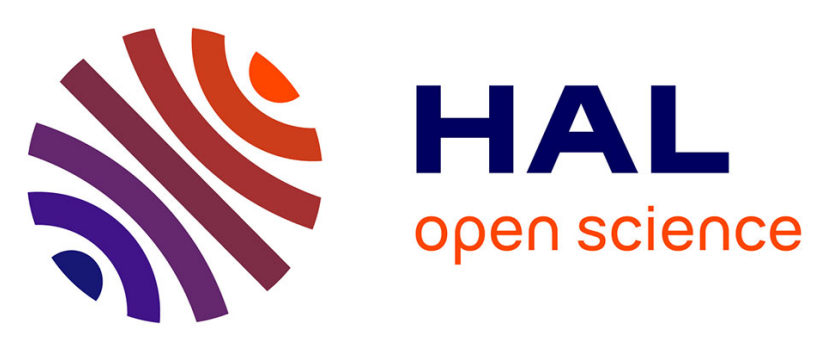

\title{
Structural incorporation of iron into Ge-imogolite nanotubes: a promising step for innovative nanomaterials
}

\author{
A. Avellan, C. Levard, N. Kumar, Jérôme Rose, L. Olivi, A. Thill, P. \\ Chaurand, D. Borschneck, A. Masion
}

\section{To cite this version:}

A. Avellan, C. Levard, N. Kumar, Jérôme Rose, L. Olivi, et al.. Structural incorporation of iron into Ge-imogolite nanotubes: a promising step for innovative nanomaterials. RSC Advances, 2014, 4 (91), pp.49827-49830. 10.1039/c4ra08840a . hal-01157201

\section{HAL Id: hal-01157201 https://hal.science/hal-01157201}

Submitted on 17 Nov 2015

HAL is a multi-disciplinary open access archive for the deposit and dissemination of scientific research documents, whether they are published or not. The documents may come from teaching and research institutions in France or abroad, or from public or private research centers.
L'archive ouverte pluridisciplinaire $\mathbf{H A L}$, est destinée au dépôt et à la diffusion de documents scientifiques de niveau recherche, publiés ou non, émanant des établissements d'enseignement et de recherche français ou étrangers, des laboratoires publics ou privés. 


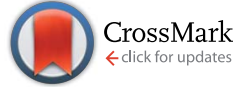

Cite this: RSC Adv., 2014, 4, 49827

Received 18th August 2014 Accepted 25th September 2014

DOI: $10.1039 / c 4 r a 08840 a$

\section{Structural incorporation of iron into Ge-imogolite nanotubes: a promising step for innovative nanomaterials $\dagger$}

\author{
A. Avellan, ${ }^{\star a b}$ C. Levard, ${ }^{a b}$ N. Kumar, ${ }^{a b}$ J. Rose, ${ }^{a b}$ L. Olivi, ${ }^{c}$ A. Thill, ${ }^{d}$ P. Chaurand, ${ }^{a b}$ \\ D. Borschneck ${ }^{a b}$ and A. Masion ${ }^{\star a b}$
}

www.rsc.org/advances

Novel iron-doped aluminogermanate nanotubes were obtained using a single step, aqueous phase synthesis protocol. These nanotubes are isostructural with imogolite, a natural occurring nanofiber, but are obtained by-product free in substantially larger quantities with aluminum substitution levels around $1 \%$. Increasing the Fe concentrations led to higher substitution levels but also to the coprecipitation of Fe (oxy)hydroxides.

Nano (structured) products carry great promise for a number of application fields because of their potential specific properties. Implementation or enhancement of these properties requires manipulation of the materials at the molecular/atomic level to tailor size, shape and surface chemistry to given needs. Nanotubular objects are of particular interest since, at this scale, all (or nearly all) atoms are surface atoms, and thus potentially reactive. In this context, aluminogermanate nanotubes $\left(\mathrm{Al}_{2} \mathrm{GeO}_{7} \mathrm{H}_{4}\right)$ are attractive on multiple levels: these Ge-analogues of the aluminosilicate imogolite $\left(\mathrm{Al}_{2} \mathrm{SiO}_{7} \mathrm{H}_{4}\right)$ (hereafter referred to as Ge-imogolite) are obtained with a low temperature, aqueous phase nucleation-growth protocol. ${ }^{\mathbf{1} 2}$ As opposed to the Si based tubes, $\mathrm{Ge}$-imogolite is formed quantitatively from molar $\mathrm{Al}$ and $\mathrm{Ge}$ solutions. ${ }^{3}$ Recent studies led to a better understanding of the formation mechanism and improved control over tube length (approx. 10 to $1000 \mathrm{~nm}),{ }^{4}$ and tube structure (crystallinity, ${ }^{5}$ single(SW) vs. double-walled (DW) nanotubes). ${ }^{6,7}$

Ge-imogolite is potentially well suited for a wide range of industrial applications (e.g. chemical sorption, ${ }^{8-10}$ catalysis, ${ }^{11-13}$

${ }^{a}$ CEREGE, CNRS, Aix-Marseille Univ, IRD, UM34, UMR 7330, 13545 Aix en Provence, France.E-mail: avellan@cerege.fr; masion@cerege.fr

${ }^{b}$ iCEINT - International Center for the Environmental Implications of NanoTechologies, CNRS, Duke University, Europôle de l'Arbois, 13545 Aix-enProvence, France

${ }^{c}$ ELETTRA, Synchrotron Light Source, 34012 Trieste, Italy

${ }^{d}$ CEA Saclay, IRAMIS, Laboratoire Interdisciplinaire sur l'Organisation Nanométrique et Supramoléculaire, 91191 Gif sur Yvette, France

$\uparrow$ Electronic supplementary information (ESI) available: XRD and AFM data. See DOI: $10.1039 / \mathrm{c} 4 \mathrm{ra08840a}$ humidity control $^{\mathbf{1 4}}$ and gas adsorption, separation and storage $\left.{ }^{15-17}\right)$. Some of these specific properties may be obtained only with prior surface functionalization of the tubes. For example, modifications of the inner wall can cause changes in the sorption properties, either by a better selectivity (e.g. $\mathrm{CO}_{2}$ sorption enhanced by one order of magnitude), ${ }^{18}$ or as side effect of tube diameter changes which increased the space between the imogolite fibers. ${ }^{19}$ There have been attempts of substituting $\mathrm{Al}$ by $\mathrm{Fe}$ in the structure of $\mathrm{Si}$-imogolite to obtain a modified reactivity. ${ }^{\mathbf{1 3 2 0}}$ For instance, the addition of $\mathrm{Fe}(\mathrm{III})$ during the synthesis of $\mathrm{Si}$-imogolite resulted in a modified imogolite with catalysis properties for the oxidation of organic compounds such as cyclohexane, toluene, benzaldehyde and chlorobenzenes. ${ }^{13}$ Another example is enhanced removal of As(v) by an imogolite-magnetite hybrid. ${ }^{20}$ However, the status of Fe atoms within the imogolite structure remains unclear.

The synthesis of by-product free, Fe-doped imogolite still remains a challenge. $A b$ initio computations suggested that a 5 to $10 \% \mathrm{Al}$ substitution by $\mathrm{Fe}$ in $\mathrm{Si}-$ or $\mathrm{Ge}$-imogolite would reduce the band gap value from 4.6 to 2.6 and from 4.2 to $1.0 \mathrm{eV}$ respectively, ${ }^{21}$ thereby conferring semi-conductor properties to Fe-doped imogolite. The case of Ge-imogolite is particularly interesting because of the ease of selectively synthesizing large amounts of single- $v s$. double-walled nanotubes. However, there is no experimental evidence of $\mathrm{Al}$ substitution by $\mathrm{Fe}$ in $\mathrm{Ge}-$ imogolite in the literature. In the present study, we describe the successful synthesis of a novel Fe-doped Ge-imogolite, where iron is incorporated in the wall structure.

Fe-doped Ge-imogolite was obtained by modifying the synthesis protocol of iron free DW Ge-imogolite ${ }^{3}$ as follows: under strictly anoxic conditions ( $\mathrm{N}_{2}$ filled glovebox), aluminum perchlorate and iron(II) perchlorate were mixed (total concentration $0.2 \mathrm{~mol} \mathrm{l}^{-1}$ ) at molar ratios $n_{\mathrm{Fe}} / n_{(\mathrm{Al}+\mathrm{Fe})}=0,0.02,0.05$ and 0.1 (hereafter referred to as $0 \mathrm{p}, 2 \mathrm{p}, 5 \mathrm{p}$, and $10 \mathrm{p}$ respectively). Iron II was used to ensure the presence of dissolved Fe monomers for the nucleation process. Tetraethoxygermanium was added $\left(n_{(\mathrm{Al}+\mathrm{Fe})} / n_{\mathrm{Ge}}=1.75\right)$ to the solution. This ratio deviates from the theoretical value of 2 for a well crystallized system. 
Here, the strategy was to deliberately create octahedral vacancies to facilitate the incorporation of the larger Fe(II) cation into the gibbsite layer. The mixture was then slowly hydrolyzed with $\mathrm{NaOH}$ to a hydrolysis ratio $\left(n_{\mathrm{OH}} / n_{(\mathrm{Al}+\mathrm{Fe})}\right)$ of 2 . The suspensions were incubated at $95{ }^{\circ} \mathrm{C}$ and then dialyzed (10 $\mathrm{kDa}$ cutoff) against ultrapure water to remove dissolved salts. The formation of tubular structures was ascertained with AFM observations (Bruker INOVA). Chemical composition (Al, Ge, and $\mathrm{Fe}$ ) was determined by ICP-AES (Horiba Ultima-C). Additional characterization was performed on freeze-dried subsets of the samples. X-ray diffraction patterns (PANalytical X'Pert Pro) were recorded using a glass capillary sample holder. Extended X-ray Absorption Fine Structure (EXAFS) is an element specific probe of the molecular environment of a given atom. Fe K-edge EXAFS spectra were collected in the transmission mode on beamline $\mathbf{1 1 . 1}$ at the ELETTRA synchrotron (Trieste, Italy). Calculated spectra were fitted to the experimental signal using the iXAFS software. ${ }^{22}$

AFM images obtained confirmed the presence of nanotubes within our samples. Typical AFM pictures of samples $0 p$ and $2 p$ are shown in Fig. 1. Similar pictures were obtained for samples $5 \mathrm{p}$ and 10p (see ESI $\dagger$ ). Tube diameter distributions were similar for $0 \mathrm{p}$ and $2 \mathrm{p}$ sample (see Fig. 1C) but shifted towards larger values with increasing [Fe] (see ESI $\dagger$ ).

The lengths of tubes vary between 30 to $150 \mathrm{~nm}$ for each sample. Within the samples with the highest Fe concentrations (5p and 10p), large globular solids of about 100-200 nm height and $500 \mathrm{~nm}$ length, were observed (see ESI $\dagger$ ) and are assumed to be co-precipitated Fe (oxy)hydroxides. The XRD patterns displayed the expected bands characteristic of the structure of well crystallized Ge-imogolite structure ${ }^{5}$ (see ESI $\dagger$ ) without additional features.
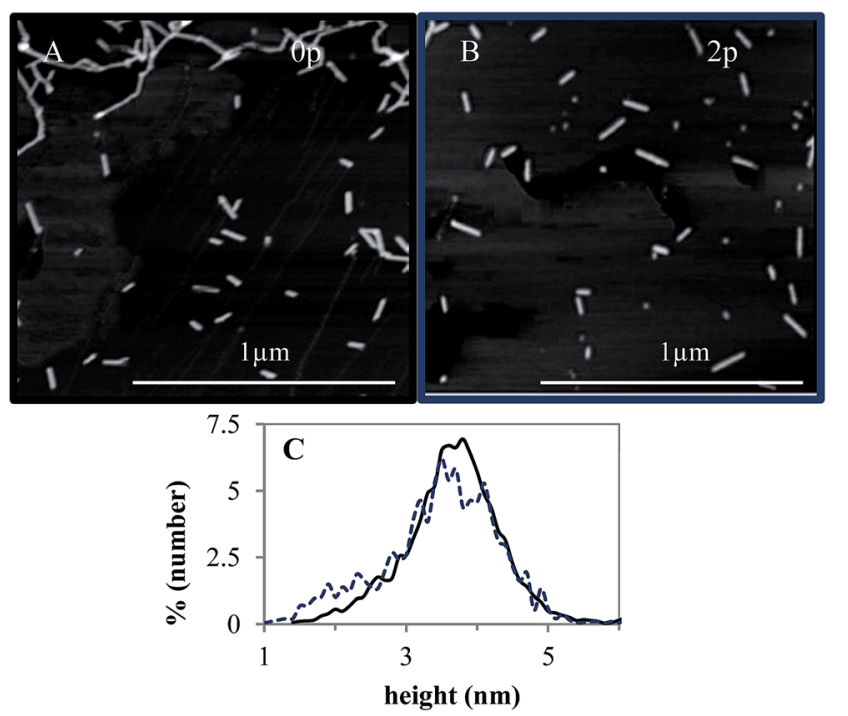

Fig. 1 AFM observation in tapping mode for samples $0 p(A)$ and $2 p(B)$ and diameter height distribution (C): solid (sample $0 \mathrm{p}$ ) and dotted line (sample 2p). Height distributions were obtained with ImageJ software, $^{23}$ based on the analysis of a minimum of 200 nanotubes, aggregates excluded.
The $n_{(\mathrm{Al}+\mathrm{Fe})} / n_{\mathrm{Ge}}$ ratio of 1.6 for the iron free sample (Table 1 ) indicates the presence of octahedral vacancies in the wall structure as expected. In the sample with the lowest $\mathrm{Fe}$ concentration, the examination of the coordination environment using EXAFS spectra analysis revealed that no Fe(II) is left in the samples. Indeed typical $\mathrm{Fe}(\mathrm{II})-\mathrm{O}$ distances are around $2.10 \AA$; however for sample $2 p$, the ligand sphere of iron consisted of $6 \mathrm{O}$ atoms at $1.99 \AA$ (Fig. 2 and Table 2), which is indicative of an octahedral coordination of Fe(III). Oxidation of the initially introduced Fe(II) most likely occurred during the incubation phase, i.e. when the containers, although closed, were removed from the anoxic environment to be placed in the oven. Chemical analyses (Table 1) indicated that only half of the initially introduced Fe was recovered in the formed tubes.

The second coordination shell around Fe was fitted with 2.1 $\pm 0.3 \mathrm{Al}$ atoms at $2.96 \pm 0.01 \AA$ (Table 2). This result demonstrates that $\mathrm{Fe}$ is incorporated into the structure of Ge-imogolite. The $N_{\mathrm{Al}}$ coordination number is significantly lower than the theoretical $3 \mathrm{Al}$ neighbors in the case of an isomorphic substitution in a well crystallized system. In our case however, the initial $(\mathrm{Al}+\mathrm{Fe}) / \mathrm{Ge}$ ratio was deliberately set below 2 in order to create tube-wall defects capable of accommodating the larger $\mathrm{Fe}(\mathrm{II}) \mathrm{O}_{6}$ octahedron (Fe(II)-O: $2.12 \AA$ ํ vs. $1.88 \AA$ for Al-O). ${ }^{24-26}$ The measured $n_{(\mathrm{Al}+\mathrm{Fe})} / n_{\mathrm{Ge}}$ ratios in the final products were below 2 as expected (Table 1), indicating the presence of octahedral vacancies in the wall structure for all samples. The Fe(III) in the final tubes is adjacent to a vacant site. It is likely that iron is incorporated into the tube wall structure in the form of $\mathrm{Fe}$ (II) cations during the initial nucleation phase under anoxic conditions. In this context, the present data suggest that (i) $\mathrm{Fe}(\mathrm{II})$, which requires more than $10 \%$ additional space compared to $\mathrm{Al}(\mathrm{III})$, is added into pre-existing wall defects with the size of two neighboring Al vacancies, or (ii) the nucleation around $\mathrm{Fe}(\mathrm{II})$ proceeded no further than $2 \mathrm{Al}$ neighbors so as to avoid structural constraints, (iii) or both. The oxidation of iron during the incubation phase eases steric constraints due the smaller size of the Fe(III) octahedra. The formation of $3 \mathrm{Fe}-\mathrm{O}-\mathrm{Al}$ linkages with subsequent bond breakage during oxidation, as well as the exchange of a structural $\mathrm{Al}$ with a $\mathrm{Fe}$ octahedron are unlikely to form from an energy point of view. Fig. 3 shows a tentative structural model of the Fe-doped Ge-imogolite derived from the present data. The absence of Fe-Fe contribution indicates the absence of Fe clusters/polymers, which suggests that all the detected iron is within the imogolite structures; this translates to a substitution level of about 1\% (Table 1).

At higher Fe content (samples 5p and 10p), shell fitting as performed previously with $2 \mathrm{p}$ sample yielded poor results. Adding a Fe-Fe contribution did not improve the fits to a satisfactory level. The obtained high values of chi-square and sigma suggest a complex multi-phasic system certainly due to the precipitation of iron (oxy)hydroxide. This hypothesis is consistent with the observation of globular phases on the AFM pictures (see ESI $\dagger$ ). To get a more detailed view of the $\mathrm{Fe}$ speciation in these systems, linear combination fitting (LCF) was performed using the spectrum of sample $2 \mathrm{p}$ as reference for Fe containing imogolite (i.e. assuming that the coordination environment of $\mathrm{Fe}$ within the tube structure does not evolve 
Table 1 Element recovery in the formed Ge-imogolite samples as measured by ICP-AES and corrected for non tubular solids (samples $5 p$ and 10p) obtained using EXAFS LCF (see Fig. 4). Recovery rates are expressed as \% of initial amounts $X_{0}$

\begin{tabular}{llclll}
\hline Sample & $\mathrm{Al}_{\text {tubes }} / \mathrm{Al}_{0}(\%)$ & $\mathrm{Fe}_{\text {tubes }} / \mathrm{Fe}_{0}(\%)$ & $\mathrm{Ge}_{\text {tubes }} / \mathrm{Ge}_{0}(\%)$ & $(\mathrm{Al}+\mathrm{Fe}) / \mathrm{Ge}$ in tube & \multicolumn{1}{c}{$\mathrm{Fe}$ in tube $(\%)$} \\
\hline $0 \mathrm{p}$ & 73 & 0 & 88 & 1.6 & 0 \\
$2 \mathrm{p}$ & 85 & 48 & 84 & 1.7 & 1.6 \\
$5 \mathrm{p}$ & 65 & 29 & 70 & 1.7 & 3 \\
$10 \mathrm{p}$ & 75 & 31 & 73 & &
\end{tabular}
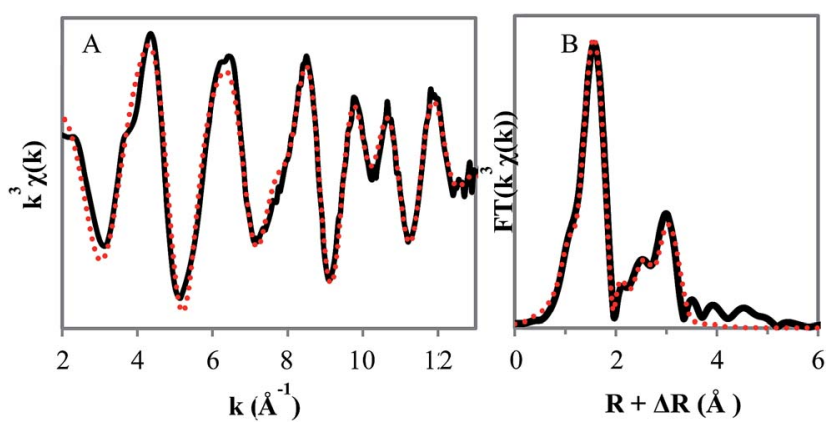

Fig. 2 EXAFS spectra $k^{3} \chi(k)(\mathrm{A})$ and Fourier transform (B) of $2 \mathrm{p}$ sample at Fe-K edge. Experimental (solid lines) and calculated signal (dotted lines) (see Table 2 for fitting details).

with Fe concentration), and the following model Fe-phases: poorly ordered ferrihydrite, 6-L-ferrihydrite, magnetite, lepidocrocite, maghemite, nontronite and goethite. The best fits were obtained with combinations of the Fe-doped Ge-imogolite and 6-L-ferrihydrite (Fig. 4). Adding additional Fe compounds did not improve the fit.

Ferrihydrite is a minor species for sample $5 \mathrm{p}$, but accounts for $40 \%$ of the signal when the Fe concentration is doubled. This non linear increase of the proportion of 6-L-ferrihydrite in the system may be the consequence of a "saturation" of the available sites (although octahedral vacancies are still detected at the highest $\mathrm{Fe}$ concentration) and/or slow Fe incorporation. The Al substitution levels calculated from the LCF proportions (see Fig. 4) and ICP-AES measurements indicate that the Fe incorporation increases with the initial iron concentration (Table 1). However one needs to keep in mind that the values for the two highest Fe concentration are no more than crude estimates because of the imprecision of LCF fitting and the assumption that the Fe binding environment, and in particular the value of $N_{\mathrm{Al}}$, is constant irrespective of the $\mathrm{Al}$ substitution

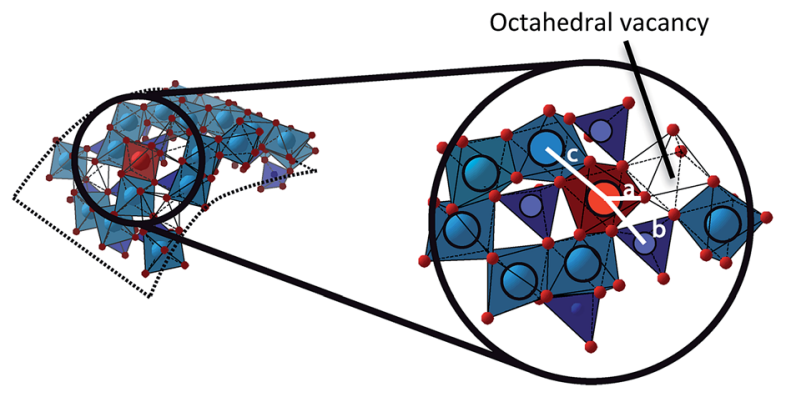

Fig. 3 Model of Ge imogolite with structural substitution of Al by Fe and interatomic distances: (a) $\mathrm{Fe}-\mathrm{O}=1.99 \AA$; (b) $\mathrm{Fe}-\mathrm{Ge}=3.34 \AA$ (c) $\mathrm{Fe}-\mathrm{Al}=2.96 \AA$. Generated by using the CrystalMaker software (blue: Al; purple: Ge; red: O; gold: Fe).

level. Whether Fe addition into pre-existing wall defects or $\mathrm{Al}$ polymerization around $\mathrm{Fe}$ is the prevailing incorporation mechanism, the present data suggest that the proportion of structural Fe within the tube may be increased beyond the $3 \%$ measured here, although it is questionable if significantly higher proportions can be achieved since the incorporation of Fe does not increase linearly with its initial concentration. Factors controlling the maximum proportion of $\mathrm{Fe}$ within the tube are probably the size difference between the $\mathrm{FeO}_{6}$ and $\mathrm{AlO}_{6}$ octahedra potentially causing lattice strain and/or the deficit of charge in the initial nucleation stage caused by the substitution of an $\mathrm{Al}^{3+}$ by a $\mathrm{Fe}^{2+}$. Both can potentially lead to growth inhibition above a certain substitution rate. From an engineering point of view, however, increasing the Fe proportion is useful only if a cost-effective separation of the tube from the Fe (oxy) hydroxide by-products is possible.

The chemical analysis revealed another interesting feature: not all the introduced Fe are recovered in the precipitated solids (Table 1). A similar phenomenon has been reported previously during the synthesis of $\mathrm{Fe}$ free $\mathrm{Ge}$-imogolite where unreacted $\mathrm{Al}$

Table 2 Structural parameters for sample $2 p$ derived from $R$-space fitting (from 1.052 to $3.360 \AA$ ) using theoretical Fe-O, Fe-Al and Fe-Ge paths generated by FEFF 6.2. Amplitude factor $=0.77 \pm 0.03$ and $\Delta E=-2.80 \pm 0.52$; Chi-square $=1071$, reduced Chi-square $=82, R$-factor $=0.014$. $R_{\mathrm{x}}(\AA \AA)$ : interatomic distance; $N_{\mathrm{x}}$ : number of neighbors; $\sigma_{\mathrm{x}}(\AA)$ : Debye-Waller factor

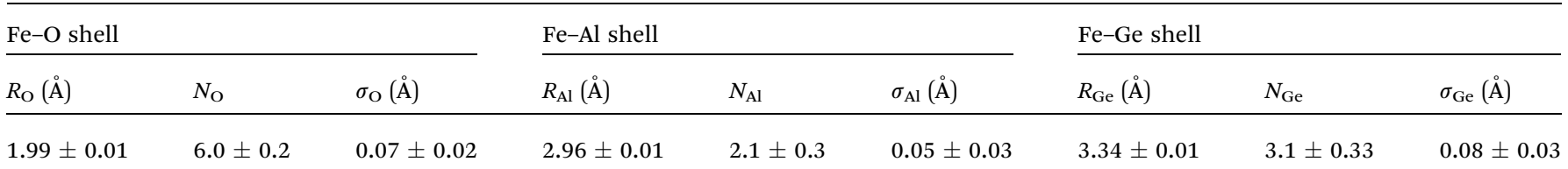




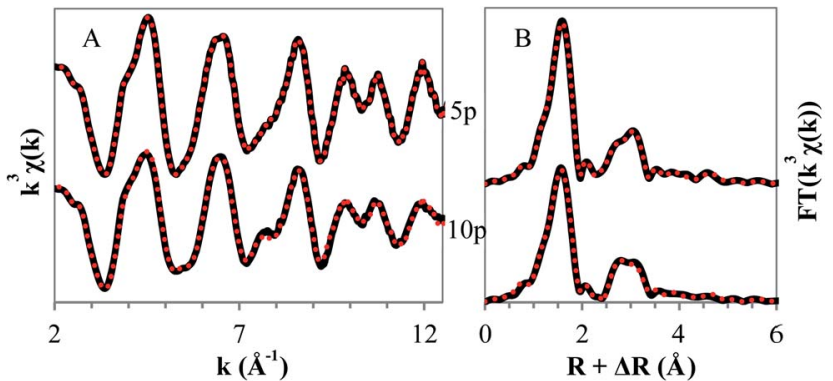

\begin{tabular}{ccccc} 
Sample & $\%$ Ge-imogolite $2 \mathrm{p}$ & $\%$ 6-L-Ferrihydrite & $\mathrm{R}$-factor & Chi-square \\
\hline $5 \mathrm{p}$ & 86 & 16 & 0.0045 & 10.32 \\
$10 \mathrm{p}$ & 60 & 40 & 0.0062 & 10.05
\end{tabular}

Fig. 4 Linear combination fitting of samples $5 p$ and 10p and its results A: EXAFS spectra $k^{3} \chi(k)$; B: Fourier transform. Solid line: experimental; dotted line: calculated.

represented approx. $30 \%$ of the initial concentration; ${ }^{27}$ in the present work this proportion was in a ca. $15-35 \%$ range. For Fe, the proportion of unreacted metal cation appears to be even larger (in order of 50\%). As opposed to $\mathrm{Al}$, it is very unlikely that the "missing" Fe is in monomers form. Our results suggest that the Fe clusters formed at low Fe concentration are smaller than the cutoff size of the dialysis membrane. However the size of these Fe phases increases with the concentration as demonstrated by the increasing proportion of non-imogolite phases in the recovered solids.

\section{Conclusions}

Novel Fe-doped Ge-imogolite nanotubes were obtained in large amounts with a simple one step synthesis in aqueous systems. $\mathrm{Fe}$ is incorporated in the structure by occupying octahedral vacancies in the curve gibbsite layer. Tubes $1 \% \mathrm{Fe}$ doping were obtained by-product free. Higher levels of Fe incorporation were achieved at the cost of co-precipitation of Fe (oxy)hydroxides which complicates the purification process. The present results demonstrate the potential of inexpensive synthesis protocol for obtaining nanotubular structures with a variety of compositions adapted for specific applications.

\section{Acknowledgements}

This work benefited from the financial support of the French ANR projects HIMO2 under contract number ANR-11-BS08-0002 and Nanomorph under contract number ANR-2011-NANO-008-04.

\section{Notes and references}

1 V. C. Farmer and A. R. Fraser, in Developments in Sedimentology, ed. M. M. Mortland and V. C. Farmer, Elsevier, 1979, vol. 27, pp. 547-553.

2 S. Wada and K. Wada, Clays Clay Miner., 1982, 30, 123-128. 3 C. Levard, J. Rose, A. Masion, E. Doelsch, D. Borschneck, L. Olivi, C. Dominici, O. Grauby, J. C. Woicik and J.-Y. Bottero, J. Am. Chem. Soc., 2008, 130, 5862-5863.
4 M.-S. Amara, E. Paineau, M. Bacia-Verloop, M.-E. M. Krapf, P. Davidson, L. Belloni, C. Levard, J. Rose, P. Launois and A. Thill, Chem. Commun., 2013, 49, 11284-11286.

5 C. Levard, A. Masion, J. Rose, E. Doelsch, D. Borschneck, L. Olivi, P. Chaurand, C. Dominici, F. Ziarelli, A. Thill, P. Maillet and J. Y. Bottero, Phys. Chem. Chem. Phys., 2011, 13, 14516-14522.

6 P. Maillet, C. Levard, E. Larquet, C. Mariet, O. Spalla, N. Menguy, A. Masion, E. Doelsch, J. Rose and A. Thill, J. Am. Chem. Soc., 2010, 132, 1208-1209.

7 A. Thill, P. Maillet, B. Guiose, O. Spalla, L. Belloni, P. Chaurand, M. Auffan, L. Olivi and J. Rose, J. Am. Chem. Soc., 2012, 134, 3780-3786.

8 Y. Arai, M. McBeath, J. R. Bargar, J. Joye and J. A. Davis, Geochim. Cosmochim. Acta, 2006, 70, 2492-2509.

9 L. Denaix, I. Lamy and J. Y. Bottero, Colloids Surf., A, 1999, 158, 315-325.

10 J. B. Harsh, S. J. Traina, J. Boyle and Y. Yang, Clays Clay Miner., 1992, 40, 700-706.

11 S. Imamura, Y. Hayashi, K. Kajiwara, H. Hoshino and C. Kaito, Ind. Eng. Chem. Res., 1993, 32, 600-603.

12 S. Imamura, T. Kokubu, T. Yamashita, Y. Okamoto, K. Kajiwara and H. Kanai, J. Catal., 1996, 160, 137-139.

13 M. Ookawa, in Clay Minerals in Nature - Their Characterization, Modification and Application, ed. M. Valaskova, InTech, 2012, p. 2708.

14 M. Suzuki, S. Suzuki, M. Maeda, S. Tomura and T. Mizota, J. Ceram. Soc. Jpn., 2001, 109, 874-881.

15 W. C. Ackerman, D. M. Smith, J. C. Huling, Y. W. Kim, J. K. Bailey and C. J. Brinker, Langmuir, 1993, 9, 1051-1057.

16 P. I. Pohl, J.-L. Faulon and D. M. Smith, Langmuir, 1996, 12, 4463-4468.

17 M. A. Wilson, G. S. H. Lee and R. C. Taylor, Clays Clay Miner., 2002, 50, 348-351.

18 D.-Y. Kang, N. A. Brunelli, G. I. Yucelen, A. Venkatasubramanian, J. Zang, J. Leisen, P. J. Hesketh, C. W. Jones and S. Nair, Nat. Commun., 2014, 5, 3342.

19 B. Bonelli, M. Armandi and E. Garrone, Phys. Chem. Chem. Phys., 2013, 15, 13381-13390.

20 N. Arancibia-Miranda, M. Escudey, C. Pizarro, J. C. Denardin, M. T. García-González, J. D. Fabris and L. Charlet, Mater. Res. Bull., 2014, 51, 145-152.

21 F. Alvarez-Ramírez, J. Chem. Theory Comput., 2009, 5, 32243231.

22 B. Ravel and M. Newville, J. Synchrotron Radiat., 2005, 12, 537-541.

23 C. A. Schneider, W. S. Rasband and K. W. Eliceiri, Nat. Methods, 2012, 9, 671-675.

24 A. Masion, D. Tchoubar, J. Y. Bottero, F. Thomas and F. Villieras, Langmuir, 1994, 10, 4344-4348.

25 A. F. Wells, Structural inorganic chemistry, Clarendon Press, 1984.

26 E. Doelsch, J. Rose, A. Masion, J. Y. Bottero, D. Nahon and P. M. Bertsch, Langmuir, 2002, 18, 4292-4299.

27 C. Levard, J. Rose, A. Thill, A. Masion, E. Doelsch, P. Maillet, O. Spalla, L. Olivi, A. Cognigni, F. Ziarelli and J.-Y. Bottero, Chem. Mater., 2010, 22, 2466-2473. 